\title{
Investigating EAP Teachers' Use and Perceptions of Gesture in General and in Corrective Feedback Episodes
}

\section{Eva Kartchava \& Abdizalon Mohamed}

This exploratory study examined the spontaneous use of gestures occurring in general as well as the corrective behaviour of two English for academic purposes (EAP) teachers at a Canadian university. Data were collected by way of an interview, lesson observation, and a stimulated recall session. Prior to the observation, each teacher was interviewed to identify practices (as they relate to gesture and $(F)$ they found effective and employed regularly in their teaching. After the lesson, the teachers watched extracts from their lessons to reflect on the use of gestures in general and in CF episodes specifically, and to explain the motivations and/or reasons behind their choices. Results indicate that the EAP teachers actively used gestures, with many occurring alongside CF moves. They were also strategic in the amount and types of both CF and gesture they used.

Cette étude exploratoire a examiné l'utilisation spontanée de gestes qui se produit en général ainsi que dans le cadre de comportement correctif chez deux enseignants d'anglais académique (EAP) d'une université canadienne. Des données ont été recueillies au moyen d'entrevues, d'observation de cours et d'une session de rappel stimulé. Avant de procéder à l'observation, chaque enseignant a fait l'objet d'une entrevue pour identifier les pratiques (en ce qu'elles avaient trait à la gestuelle et à la rétroaction corrective) qu'ils trouvaient utiles et employaient régulièrement quand ils enseignent. Après la leçon, les enseignants ont visionné des extraits de leur leçon afin de réfléchir à l'utilisation de gestes en général et lors de la rétroaction corrective en particulier, ainsi que pour expliquer les motivations et/ou les raisons qui sous-tendaient leurs choix. Les résultats indiquent que les enseignants d'EAP utilisaient la gestuelle de façon active, dont une grande partie se produisait en même temps que les gestes de rétroaction corrective. La quantité et le type de gestuelle et de rétroaction corrective étaient utilisés de façon stratégique.

Keywords: oral corrective feedback, gestures, English for academic purposes, teacher practices, teacher perceptions 
Researchers have systematically analyzed the role of nonverbal cues (movements of the body, arms, or head) in human interaction (Manusov, 2016) since these have been shown to enhance information provided verbally (McNeil, 2006). In second language (L2) education, the focus has predominately been on the role of gestures in classroom interactions and learner uptake. However, investigations of gesture use by L2 teachers in the delivery of corrective feedback (CF) (i.e., information that alerts learners to inaccuracies in their output) and the rationale they assign to these moves have been limited (Nakatsukasa \& Loewen, 2017), particularly in the English for academic purposes (EAP) context. The study reported here contributes to this body of research by exploring the use of gesture, $\mathrm{CF}$, and a combination of the two (gesture in CF episodes) in the discourse of two EAP teachers. It also provides a rationale for the teachers' decisions and practices. By doing so, it answers the call for investigations that not only identify the extent to which gestures are used in providing feedback across contexts and linguistic targets (Nakatsukasa \& Loewen, 2017), but also explain the reasons for these from the perspective of the teachers' themselves.

\section{Literature Review}

Gestures (i.e., movements of the hands, arms, and head, Sime, 2006) have been shown to occur frequently, either on their own or in conjunction with speech, and to impact teaching in L2 and other subject classrooms (see Nakatsukasa, in press; Nakatsukasa \& Loewen, 2017 for review). In the language classroom, gestures have been used to aid the development of L2 vocabulary, pronunciation, grammar, and comprehension (e.g., Dahl \& Ludwigsen, 2014; Gluhareva \& Prieto, 2017; Macedonia et al., 2011; Morett \& Chang, 2015; Nakatsukasa, 2016, 2019; Repetto et al., 2017; Sime, 2006, 2008; Sueyoshi \& Hardison, 2005; Tellier, 2008). Several observational studies have reported on the frequency and types of gesture L2 teachers use and their purposes (e.g., Allen, 1995, 2000; Hudson, 2011; Lazaraton, 2004; Smotrova, 2017; Smotrova \& Lantolf, 2013). Specifically, they have shown that teachers employ gestures to facilitate learners' understanding of the L2 and classroom discourse. Lazaraton (2004), for example, demonstrated how one English L2 teacher used nodding and hand gestures to illustrate word meanings in her lessons. Smotrova (2017) reported on an English as a Second Language (ESL) teacher's use of gestures to explain vocabulary, grammar, and pronunciation. Similarly, Allen (2000) examined gestures and facial expressions that a high school teacher of Spanish employed to direct turn-taking, encourage participation, question learner responses, point out referents identified in speech, express emotion, explain vocabulary items, and to illustrate culturespecific moves. Working with an instructor teaching ESL at the university level, Hudson (2011) observed her use gestures to describe grammatical concepts, illustrate phonetic and phonological notions, support lexical 
meaning (of objects, abstract/concrete ideas, and actions), and to manage the classroom (in terms of task structure, turn-taking, and comprehension checks).

Gestures may especially be helpful for lower-proficiency learners (Dahl \& Ludwigsen, 2014; McCafferty, 2002; Sueyoshi \& Hardison, 2005). Sueyoshi and Hardison (2005), for example, showed that ESL learners of beginner proficiency were better able to understand a video-recorded lecture when the input contained gestures while their advanced counterparts were able to do so effectively without gestures. Gestures also helped comprehension in weekly oral interactions of an ESL learner and his tutor, who together created and operated within zones of proximal development that promoted language learning (McCafferty, 2002). While the learner used gestures to seek understanding and convey his thoughts, the tutor relied on gestures mostly for such pedagogical purposes as eliciting vocabulary and confirming comprehension. Working with English native-speaking schoolchildren in the United States and those learning English in Norway, Dahl and Ludwigsen (2014) asked them to first watch four short videos that described cartoon images in English, either with or without the speaker's gestures, and to then draw the images. They found that gestures facilitated comprehension of the English as a Foreign Language (EFL) learners, yielding accurate drawings as a result; presence or absence of gestures, however, made no difference to the comprehension of the native speakers.

To explain and categorize the observed gestures, most studies have used McNeil's (1992) gestural classification, which includes five types: metaphoric, iconic, deictic, beats, and emblems. Iconic and metaphoric gestures are similar in that they both represent ideas, showing and modelling shapes to communicate. However, they differ in that iconic gestures model concrete objects or events (e.g., a speaker arcs his/her fist to form a cup and drink from it while saying "I drink from a cup") whereas metaphoric gestures depict abstract ideas (e.g., a speaker arcs his/her fist to form a cup and drink from it while saying "Let's take a drink from the fountain of knowledge"). Deictic gestures point out objects or referents, as in a teacher with his/her fist clenched and the index finger extended pointing at student. Beats are rhythmic movements usually used to add emphasis to something in the speech. Finally, emblems are gestures governed by cultural conventions that convey a meaning that can be understood without speech (e.g., the "OK" sign). When teaching pronunciation, the instructor in Hudson (2011), for example, used metaphoric gestures to indicate the length of vowel sounds (by extending both arms forward and stretching them with "it's long," p. 142), iconic gestures to illustrate the difference between short and long vowels (by touching the sides of her mouth with both index fingers and sliding them up and down repeatedly, saying "Your mouth is more short <.> this way," pp. 147-8), deictic gestures to indicate syllable stress (e.g., on the word "thirteen" by moving index finger up and then down to chest level, pp. 154-5), 
beats to explain syllabification (e.g., lightly tapping the bottom of her right palm twice, the teacher said: "Repeat. Men 'n' women," p. 155), and emblems to indicate approval or check comprehension (with thumb up/down) ${ }^{1}$.

More recently, several researchers have examined the role of gestures in CF episodes. Although the utility of CF in L2 development has been ascertained by a large body of research (e.g., Li, 2010; Loewen, 2012; Lyster et al., 2013; Mackey \& Goo, 2007; Russell \& Spada, 2006; Sheen \& Ellis, 2011), there is evidence that a number of factors can impede its noticeability and effectiveness. These primarily include: instructional context (Sheen, 2004, 2006; Loewen \& Philp, 2006; Lyster \& Mori, 2006), feedback strategy (Goo \& Mackey, 2013; Lyster \& Ranta, 2013), error type (Brown, 2014; Kartchava \& Ammar, 2014; Mackey, 2006), and salience (Ammar, 2008; Ellis et al., 2006; Kartchava \& Ammar, 2013; Mackey \& Philp, 1998; Nassaji, 2011). Gestures used alongside oral CF may, however, increase the saliency of feedback by helping learners to better understand the linguistic target of a particular feedback move and retain what they have learned (Nakatsukasa \& Loewen, 2017). The need to recognize the corrective intent of CF is necessary for learners to act on their L2 knowledge and improve performance (Nabei \& Swain, 2002). After all, any "utterance can count as feedback or correction only if a learner is willing to construe some bit of language as expressing a corrective intention on the part of some speaker" (Carroll, 2001, p. 348). Since gesture and speech tend to co-occur in human communication and within the classroom, investigating the utility of gesture in alerting learners to the corrective information that verbal CF episodes contain is, hence, of merit.

Research that has examined the use, effectiveness, and noticeability of gestures in CF provision (e.g., Davies, 2006; Inceoglu, 2015; Kamiya, 2012; Kartchava, 2019; Nakatsukasa, 2016, 2019; Wang, 2009; Wang \& Loewen, 2016), however, is limited. Having observed and analyzed 65 hours of interaction in nine ESL classrooms, Wang and Loewen (2016) found that teachers incorporated gestures and other nonverbal behaviour (e.g., head movements) while providing CF $60.2 \%$ of the time, with head movements (nodding and shaking, 32\%) and deictic (27\%), iconic (12\%), and beat (11\%) gestures dominating the discourse. Interestingly, both implicit and explicit $\mathrm{CF}$ types were accompanied by nonverbal cues. Explicit feedback types tend to be more noticeable and effective compared to implicit strategies, albeit the latter are more effectual in the long term (Li, 2010). The first to observe and classify feedback types in an L2 classroom were Lyster and Ranta (1997), who also analyzed learners' responses to teachers' feedback (i.e., uptake). Their taxonomy of CF strategies includes recasts, explicit correction, and prompts. Recasts and explicit correction provide learners with targetlike reformulations of their output. Prompts, which can take the form of elicitation, repetition, clarification, or be metalinguistic in nature, are used to provide cues as to the locus and nature of the error, with the goal of having the learner self-correct. While a metalinguistic prompt and explicit correction 
are arguably more salient than implicit feedback, the degree of explicitness/ implicitness is often determined by how a feedback type is implemented (Sheen \& Ellis, 2011).

Davies (2006) observed the use of "purely paralinguistic" feedback that was devoid of "any verbal feedback at all" (p. 845) and its impact on learner uptake in Japanese EFL classes. The results showed that the paralinguistic feedback resulted in $100 \%$ of uptake, and that when implicit verbal CF types (recasts and clarification requests) were provided alongside paralinguistic cues, they yielded more uptake than when used alone. The teachers were strategic in their use of nonverbal cues in that they incorporated them to highlight the corrective focus of the implicit CF strategies; yet, when the focus was on meaning, the implicit CF types were supplied without paralinguistic support. Wang (2009, cited in Nakatsukasa \& Loewen, 2017) compared the effectiveness of oral $\mathrm{CF}$ and $\mathrm{CF}$ accompanied by nonverbal cues among the ESL learners in Wang \& Loewen (2016). The findings showed that when nonverbal cues were used alongside verbal CF, learners' accuracy scores on immediate $(73 \%)$ and delayed $(61 \%)$ posttests were notably higher than when only oral CF was supplied (56\% posttest; $47 \%$ delayed posttest). In another non-interventionist study, Kartchava (2019) examined one ESL teacher's use of nonverbal cues in oral CF episodes and their effectiveness in helping learners recognize the intended corrective focus of verbal feedback provided to errors on past tense and questions. The teacher provided verbal CF on average every minute during the student-centered portion of the lesson and accompanied $77 \%$ of it with nonverbal cues that included the body (52\%) and deictic gestures (48\%). Recasts were supported by gestures $63 \%$ of the time whereas $37 \%$ for prompts. Analysis of uptake showed that the learners recognized the corrective nature of recasts accompanied by nonverbal cues $76 \%$ of the time and $100 \%$ for prompts.

Focusing exclusively on recasts, Nakatsukasa (2016) investigated their effectiveness when provided with and without gestures on the acquisition of locative pronouns. Three groups of low-intermediate ESL learners participated in information-gap tasks, during which one group received recasts, another group was provided with a combination of recasts and gestures, and the third group served as the control. Based on the posttest scores, the learners in both CF conditions benefitted, with the recasts + gesture group maintaining the gains on the delayed posttest. However, no significant differences between the two experimental conditions were found when Nakatsukasa (2019) examined recasts provided with or without gestures on the acquisition of the English regular past tense. While these studies provide some evidence for the positive role of gestures in CF provision, it is premature to draw any definitive conclusions on the prevalence and effectiveness of nonverbal behaviour in feedback provision, especially as they pertain to various instructional contexts, linguistic targets, and student populations. To gain a better understanding of how teachers use nonverbal behaviour in general and 
alongside CF episodes, this study observed the gestures two university-level EAP teachers employed and juxtaposed against their thoughts on gesture use gathered before and after the observations. Specifically, the study was guided by these research questions:

1. To what extent do university-level EAP teachers use nonverbal cues in their classes in general?

2. To what extent do university-level EAP teachers use nonverbal cues alongside corrective feedback episodes in their practice?

3. What are the reasons for this use?

\section{Methodology}

\section{Setting}

The study was carried out at a university-based EAP program in Canada that serves students who are non-native speakers of English and who do not fully meet the English language proficiency requirement set for admission by the university. These students, however, are granted admission into their selected degree program with the condition that they complete and successfully pass one or more EAP courses as determined by their score on a standardized English language proficiency test at the time of admission. That is, if a learner receives a test score of 5.0 (out of a maximum score of 9.0 on IELTS), he or she will be placed in the beginner-level course; if the score is 5.5, then the learner is sent to the intermediate-level course; the score of 6.0 merits admission at the advanced level. Students are allowed to take one full course from their selected major when enrolled in the beginner level, two majorrelated courses for the intermediate level, and three courses at the advanced level. The learners spend 13 weeks in an EAP course that includes 78 hours of contact hours, the majority of which are spent in the classroom and 10\% are allocated for the language laboratory. Successful completion of each course level depends upon students' performance on various summative and formative assessments (e.g., presentations, essays, assignments, etc.) with a cumulative grade requirement of a " $\mathrm{C}$ " $(60 \%)$ and above for progression to the next level.

With the focus on general EAP, the program emphasizes the development of universal academic skills, language forms, and study tasks common across many disciplines as opposed to a specific one (Hyland, 2006). This is, in large part, due to the heterogenous composition of the classes with students from different majors, making it impractical, if not impossible, to cater to the specific language needs of one particular content course or discipline. Instead, the teachers use an overarching and discipline-neutral course theme to design tasks that assist learners in acquiring various skills relevant to 
the academe. Common tasks in the program include writing essays and reflections, preparing reports, participating in discussion groups, engaging in text analysis, and delivering oral presentations.

\section{Participants}

The participants of this study were two EAP instructors, David and Marcia (pseudonyms), and their students $(N=48)$. The two were native speakers of English with extensive teaching experience. David (52 years old) had over 12 years of teaching experience in various English as second/foreign language instructional settings, including seven years in the EAP program. He held a master's degree in applied linguistics, with a specialization in Teaching English as a Second Language (TESL), and a Certificate in Teaching English to Speakers of Other Languages from Cambridge (CELTA). Marcia (55 years old) had over 20 years of experience teaching English both in Canada and abroad. She held a master's degree and a doctorate in education, specializing in L2 pedagogy, and a Certificate in TESL. She had 10 years of EAP teaching experience. The two teachers had taught all of the levels in the EAP program, and Marcia also had had experience teaching in other university-level academic English programs.

At the time of the study, David was teaching the intermediate-level EAP course whereas Marcia was teaching the beginner-level proficiency class. The average age of the students ranged from 16 to 25 years old (average of 20 years old). The majority of them originated from China and the Middle East. While the students $(n=19)$ at the beginner level had little to no previous experience with academic English, many at the intermediate level $(n=29)$ were taking the second EAP course at the university.

\section{Materials and Procedures}

To collect the data, interview, classroom observation, and a stimulated recall session were used with both teachers. The interview was conducted first to identify the participants' views on their teaching practice in general and on the use of gestures and CF in particular. The interviews proved instrumental in understanding the role of context the teachers assigned to their practice and how they felt it affected the gestures they employed. Lesson observations, in turn, allowed for a comparison of what the teachers said they did and the actual manifestations of these behaviours in practice. Finally, the stimulated recall session identified the instructors' thoughts on the observed use of gestures and CF. All tools were piloted with another EAP instructor of similar educational and professional background at the university.

\section{The interview}

The 12 open-ended questions that made up the interview were structured in line with the recommendations made by Dörnyei (2007) and probed the 
teachers' professional and educational backgrounds (2 items), teaching approach(es) preferred/utilized (4 items), perceptions they held on gesture use and CF (4 items), and thoughts on the efficacy of their teaching ( 2 items). The first two questions were introductory in nature and were used to ease the interviewees into the process as well as to set the tone for the rest of the interview. The next four questions zeroed in on the teachers' preferred teaching approach(es), lesson planning methods, teaching strategies, and assessment techniques. The remaining four questions focused on the teachers' perceived use and thoughts on CF (With your students, is your primary focus more fluency or accuracy? What are some ways in which you try to achieve fluency/ accuracy/ a balance between the two? Do you believe there are things you can do better, or change, to address their fluency/accuracy issues more effectively?) and gestures (Do you implement nonverbal behaviour in your teaching? Explain.) present in their teaching practice. The last two questions sought the teachers' reflection on the efficacy of their practice and invited other pertinent information the participants felt was not addressed or wanted to add. Each interview took one hour to complete and was audio-recorded.

\section{Classroom observation}

Both participants were observed individually teaching their regular classes in the third week of the semester. To ensure the setting is as authentic as possible, the teachers determined the time for the observation and the lesson topic(s). They asked that only two hours of a three-hour class be video recorded as the remaining time was spent by students working independently in a language laboratory. The video camera was placed at the back of the classroom to ensure that the instructor was in view most of the time and to avoid causing distraction or negatively influencing the participants' behaviour (Dörnyei, 2007; Gibson \& Brown, 2009). Students' reactions to the teachers' gestures and $\mathrm{CF}$ were also recorded to support stimulated recall sessions.

\section{Stimulated Recall Session}

The stimulated recall sessions allowed for an exploration of the instructors' thoughts on gesture use, especially when these accompanied CF moves. The classroom observations revealed a total of four CF episodes in which gestures were used by each teacher. To probe their thoughts on what they saw, each participant was presented with their four video clips (averaging 2 minutes in length), one at a time. For each clip, the teachers were free to pause, replay, rewind, or fast-forward the video as needed. As soon as the video was paused, in line with Gass and Mackey's (2000) recommendations, questions such as Could you describe for me what you see in this clip? and What were you thinking while you are undertaking this [specify which] activity? were posed. Whenever necessary, more attention directing questions followed. These took the form of Can you remember what you were thinking when [event]? 
and could focus on the activity being done, reasons for doing that specific activity, motivations for $\mathrm{CF}$ provision on a specific issue, and a rationale for gesture use and their types. The process was repeated until all clips were addressed, with the whole session audio-recorded and lasting approximately 45 minutes. Although stimulated recall is seen as more informative if held shortly (within 2-3 days) after the target event, the participants were unable to meet before a week's delay. To mitigate possible memory gaps, video stimuli were used to contextualize each episode and facilitate recall.

\section{Data analysis}

A multimedia annotation software ELAN Version 5.8 (ELAN, 2019) was used to transcribe and analyze the data as it reduces the tediousness, difficulty, and errors that manual transcribing and coding are prone to (Brugman \& Russel, 2004; Wittenberg et al. 2006). The teacher interviews and stimulated recall sessions were transcribed using the software; they were later analyzed using discourse coding techniques and coded in ELAN. For the interviews, the aim was to analyze the participants' responses to identify their views about $\mathrm{CF}$ and gesture use. The responses were analyzed using holistic coding (Saldaña, 2016) that allowed the researchers to identify general themes in the teachers' responses. This type of coding is deemed especially useful when the researcher has already established particular topics of interest (as in the themes embedded in interview questions) and can analyze "self-standing units of data [such as] vignettes or episodes" (p. 166) holistically (as chunks). The same coding was applied to the responses supplied in the stimulated recall sessions. The generated codes were submitted into ELAN to search the recordings for particular text or reference. An annotation statistics tool in ELAN allows for automatic generation of statistical information on the codes, such as total number of annotations, occurrences of individual annotations, frequency, average duration of each annotation, minimal and maximal duration, median duration and latency. The annotation feature aided in identifying the common views among the teachers about their general $\mathrm{CF}$ and gesture use (shared in the interviews) as well as the reasons why they used specific gestures and feedback types within the CF episodes (as reported in the stimulated recall sessions).

The first instructional hour of each lesson was selected for analysis due to it being the primary instructional period where the majority of the teacherstudent interactions occurred, with the latter part of the lesson mainly consisting of student activities and interactions centered on discipline and task administration. This period was examined to determine (1) to what extent the teachers used gestures and provided feedback in general, (2) if gestures were present in CF episodes (i.e., an instance when the teacher addressed an error and waited for the learner's response - "error treatment sequence," Lyster \& Mori, 2006, p. 280), and (3) what types of gesture and feedback 
were used. Additionally, the function a gesture served was considered and for corrective feedback episodes, the error the feedback move addressed was noted. Lyster and Ranta's (1997) taxonomy of CF strategies was used to identify and classify the observed feedback types.

Gestures were differentiated from other movements in that they entailed a communicative intent and were used by the teachers alongside explanations of item or form. Movements to address bodily needs, such as scratching the face or changing hand position due to discomfort, were not considered for they usually do not serve any intentional communicative purpose on the part of the speaker even though the listener may still be able to derive information from them (Kendon, 2004). Gesture types were identified using McNeil's (1992) taxonomy whereas gesture communicative functions were classified in line with Kong et al.'s (2015) system. In addition to the five gesture types included in McNeil's classification, for the purposes of this study, a sixth category ("ambiguous") was added to account for gestures that presented a challenge in attribution. For example, the emblem gesture classification was applied if a participant lifted up their hands to their shoulder with a clenched fist and the index finger sticking out, moving it horizontally side to side (i.e., finger wag). If the same gesture was done without the finger sticking out and no contextual clues in the speech referencing its meaning, it would be classified as ambiguous.

Since two gestures coded as one gesture type (e.g., deictic) could simultaneously serve two separate communicative functions in relation to speech content, it is important to differentiate them. For example, if a teacher points to a student and says, "Can you come up to the board and write the answer?", the gesture is classified as deictic as it specifies the intended referent. However, if the teacher verbally identifies the referent with "James, can you come up to the board and write the answer?" and then makes the same deictic gesture, the gestural function changes to complementing the information already available in speech since no additional information is communicated by the gesture. According to Kang et al.'s (2015) taxonomy, there are seven functions that gestures can serve. As Table 1 shows, gestures can (1) provide additional information, (2) complement/enhance speech content, (3) give alternate information, (4) guide/control flow of speech, (5) emphasize intonation/prosody, (6) aid lexical retrieval and/or (7) reconstruct lexical sentence. The coding of function was done in accordance with the context of gesture production and how it related to the speech content; only the primary function was coded. When attribution of function to a gesture was impossible, it was coded as "ambiguous." 
Table 1

Gesture Functions (adapted from Kang et al., 2015, p. 101)

\begin{tabular}{ll}
\hline Function & Definition \\
\hline $\begin{array}{l}\text { Provide additional } \\
\text { information }\end{array}$ & $\begin{array}{l}\text { The content of the gesture gives } \\
\text { additional information related to } \\
\text { the speech content }\end{array}$ \\
\hline $\begin{array}{l}\text { Enhance/complement } \\
\text { speech content }\end{array}$ & $\begin{array}{l}\text { The gesture enriches the } \\
\text { meaning conveyed in speech }\end{array}$
\end{tabular}

Example

A speaker says the word

"open" while depicting a twisting motion in the air, indicating the action to open a jar. Here, the gesture focuses on opening a container, not other objects.

A speaker uses his finger to depict the action of switching off the light when saying "I switched off the light before I slept."

\begin{tabular}{lll}
\hline $\begin{array}{l}\text { Give alternate } \\
\text { information/ replaces } \\
\text { speech }\end{array}$ & $\begin{array}{l}\text { The gesture carries meaning } \\
\text { that is not included in speech } \\
\text { content }\end{array}$ & $\begin{array}{l}\text { A speaker produces the } \\
\text { thumbs up sign in reply to the } \\
\text { question of "Are you ready to } \\
\text { start?" }\end{array}$ \\
\hline $\begin{array}{l}\text { Guide/control flow of } \\
\text { speech }\end{array}$ & $\begin{array}{l}\text { The gesture reinforces the } \\
\text { rhythm of the speech }\end{array}$ & $\begin{array}{l}\text { A speaker moves his/her } \\
\text { horizontal, downward-facing } \\
\text { open fist up and down while s/ } \\
\text { he speaks in motion with the } \\
\text { rhythm of the speech. }\end{array}$ \\
\end{tabular}

\begin{tabular}{ll}
\hline Emphasize intonation/ & When a speaker uses a gesture \\
prosody & to emphasize meaning
\end{tabular}

A speaker with a close fist forcefully pushes the hands down from shoulder level at the target word.

\begin{tabular}{lll}
\hline Aid lexical retrieval & $\begin{array}{l}\text { The gesture facilitates lexical } \\
\text { access when a speaker } \\
\text { attempts to produce a target } \\
\text { word after gesturing at times of } \\
\text { word-finding difficulty }\end{array}$ & $\begin{array}{l}\text { A speaker pauses mid- } \\
\text { sentence and says, speaking } \\
\text { to his/herself, "what's the } \\
\text { word? It's on the tip of my } \\
\text { tongue," making an iconic } \\
\text { gesture depicting a cup } \\
\text { following which the word "cup" } \\
\text { is retrieved. }\end{array}$ \\
\hline $\begin{array}{l}\text { Aid lexical sentence } \\
\text { reconstruction }\end{array}$ & $\begin{array}{l}\text { A gesture to indicate difficulty } \\
\text { in sentence construction, } \\
\text { and refinement of sentence } \\
\text { structure is noticed after the use } \\
\text { of this gesture }\end{array}$ & $\begin{array}{l}\text { Same as above, but on a } \\
\text { sentence level. }\end{array}$ \\
\hline Ambiguous & $\begin{array}{l}\text { A specific function cannot be } \\
\text { attributed to the gesture }\end{array}$ & \\
\hline
\end{tabular}


The annotation statistics tool in ELAN was used to code and then generate frequency information on the gesture types and functions. Twenty-five percent of the data (i.e., two 15-minute video clips, one per teacher) were analyzed by two independent raters to ensure the coding reliability. The inter-rater reliability achieved was $90 \%$, with disagreements settled through discussion.

\section{Results}

\section{Reported CF and gesture use}

An analysis of the interviews revealed key perceptions about $\mathrm{CF}$ and gesture use consistently highlighted by the two teachers. For CF, these included: (1) the facilitative role of CF in L2 learning; (2) utility of CF codes/symbols when providing feedback to writing; (3) amount and type of CF are contextdependent; and (4) preference for $\mathrm{CF}$ that encourages self-correction. Both David and Marcia reported using CF regularly in their teaching as they saw it as facilitative of learning. They were selective of when to supply CF, basing its use on the linguistic domain (e.g., grammar, lexicon, pronunciation) being addressed ("...there are other times when I focus on accuracy. Maybe if we are doing pronunciation exercises, then... of course, I will ask them [the students] to focus on accuracy", Marcia) and the purpose of a particular task (e.g., pronunciation activities, creating a journal). For Marcia, in particular, CF provision needs to be coupled with a task (e.g., student reflection) that promotes focus on form to yield long-term gains: "I found that the feedback on the papers, unless you physically do something with the feedback it doesn't produce any gain."

The use of codes/symbols when providing written $\mathrm{CF}$ was something the teachers adhered to and even trained their learners to recognize: “...for most of the corrections, $80 \%$ of them, I'm writing code. [...] I've already talked [with the students] about several of these [i.e., the codes], like comma splices, fragments, and all these things." (Marcia). Both teachers saw the codes useful in providing feedback to common errors.

They also deemed the type and amount of CF provided to be contextually dependent. For David, for example, the amount of CF provided is dependent on students' familiarity with the content at hand and their learning stage (e.g., beginning of the semester vs. its end): "When we first introduce things [i.e., the content to be studied], there is an acceptable level [of leniency afforded in addressing the accuracy of the work]. After you've done it five or six times, you're wanting it [i.e., the student's work] to be really good..." Marcia, in turn, adapts the type of CF she provides (e.g., explicit vs. implicit feedback) based on the students' proficiency level and/or the curriculum that is to be 
followed: "When it's something I don't think they'll know, or shouldn't know, I'll just give them the correction."

Although David did not specify the type of CF he generally uses, Marcia was explicit in preferring $\mathrm{CF}$ types that encourage students to self-correct (i.e., prompts) for she saw them as not only more effective in facilitating learning (compared to recasts) but also leading to learner independence: "You're not going to learn if I correct it for you, you're only going to learn if you figure out what you're doing wrong"; "I like to prompt rather than just recast"; " [when a prompt is provided], it kind of tells them, are you sure this is not two sentences instead of one? And then they can think, oh Ok, I should fix something here. So again, trying to make them more independent."

In terms of their perceptions on gestures, the teachers saw them as (1) vital to their teaching practice; (2) a tool to manage students' emotions and the classroom, and (3) being facilitative of L2 learning. Both teachers saw gestures as integral to their teaching practice, attributing it a central role in engaging students' attention in the classroom. For Marcia in particular, gesture use was so crucial to her teaching practice that she could not envision herself teaching without gestures: "It's central to me... I can't imagine teaching without my whole body." David, in turn, saw gestures primarily as a tool to appear animated and to engage his students' attention: "When I'm teaching, I try to intentionally be more animated....being a little bit more animated helps. As a teacher, we all try to be engaging."

They also saw gestures as a tool to manage the classroom and students' emotions, with Marcia using gestures to "ramp up" or motivate the students. Similarly, David used gestures as a means to reduce student anxiety: "[I provide] a lot of feedback to the student like nodding and smiling, it helps them feel more comfortable." He also used gestures to indicate breakdowns in communication or a need for repair: "...backchannelling some [gestures], so letting them know [whether] what they're saying makes sense [or not]."

Finally, both teachers saw gestures as being facilitative of L2 learning. For David, gestures help "reinforce verbal...if you can add the facial, nonverbal, they [the students] understand it much clearer." Furthermore, gestures are particularly useful in clarifying and conveying meanings or concepts that would otherwise be too complex to convey verbally (e.g., explaining the meaning of the word "trip"), especially to students of limited proficiency: "[...] as opposed to just describing what "trip" means, that's hard, you can just pantomime it a little bit" (David).

\section{Observed CF and Gesture Use}

The lesson videos were analyzed for instances of gesture and CF. The presence of gestures was identified in general and within CF episodes. As Table 2 demonstrates, the teachers used gestures, with Marcia employing them more extensively $(n=1000)$ than David $(n=561)$. As for the gesture 
type, deictic $(n=554)$, metaphoric $(n=618)$, and beats $(n=294)$ dominated classroom teaching for both participants, accounting for a combined average of $94 \%$ of the total gesture use. The iconic $(n=63)$ and emblem $(n=7)$ gesture types were used the least, accounting for a combined $4.5 \%$ of all the gestures. Only $1.6 \%(n=25)$ of gestures the teachers used was classified as ambiguous. Notably, Marcia's use of the metaphoric $(n=448)$ and beat $(n=203)$ gesture types was more frequent.

Table 2

Number of Gesture Use across Teachers

\begin{tabular}{lll}
\hline Gesture type & David & Teacher \\
\hline Deictic & $269(48 \%)$ & $285(28.5 \%)$ \\
Iconic & $16(2.8 \%)$ & $47(4.7 \%)$ \\
Metaphoric & $170(30.3 \%)$ & $448(44.8 \%)$ \\
Emblems & $5(0.9 \%)$ & $2(0.2 \%)$ \\
Beats & $91(16.2 \%)$ & $203(20.3 \%)$ \\
Ambiguous & $10(1.8 \%)$ & $15(1.5 \%)$ \\
\hline Total & 561 & 1000 \\
\hline
\end{tabular}

The teachers used these gestures with purpose (Table 3), the most frequent of which were to enhance/complement $(n=806)$, provide additional information $(n=322)$, and guide/control the flow of speech $(n=213)$, accounting for $86 \%$ of the total gesture use. Gestures were also used to provide alternate information $(n=95)$ or emphasis $(n=88)$ to speech. They were used the least for the purposes of lexical retrieval $(n=6)$ or sentence reconstruction $(n=4)$. Only $1.8 \%(n=27)$ of functions could not be unequivocally assigned. Interestingly, Marcia relied on gestures to enhance speech content $(n=514)$, guide speech flow $(n=149)$, and emphasize spoken content $(n=62)$ noticeably more than David ( $n=292,54$, and 26, respectively). 
Table 3

Communicative Functions of Gestures Used across Teachers

\begin{tabular}{lll}
\hline Gesture communicative function & Teacher & Marcia \\
\hline Provide additional information & 127 & 195 \\
Enhance/complement speech content & 292 & 514 \\
Give alternate information/ replace speech & 36 & 59 \\
Guide/control flow of speech & 64 & 149 \\
Emphasize intonation/prosody & 26 & 62 \\
Aid lexical retrieval & 0 & 6 \\
Aid lexical sentence reconstruction & 0 & 4 \\
Ambiguous & 16 & 11 \\
\hline Total & 561 & 1000 \\
\hline
\end{tabular}

As Table 4 shows, each teacher provided CF a total of four times in the hour observed, with the total time being $7 \mathrm{~min} 62 \mathrm{~s}$ for David and $7 \mathrm{~min} 47 \mathrm{~s}$ for Marcia. The teachers focused on errors in morphosyntax, lexis, pronunciation, and word choice. Both teachers favoured addressing errors by combining a number of techniques within each CF episode, prioritizing explicit correction types. Prompts (metalinguistic cues, clarification request, elicitation) were used to encourage self-correction whereas only one recast was supplied in response to a phonological error (see a portion of the CF episode below).

Example of CF episode (partial)

Marcia: Say the word (Metaphoric gesture used for "word" in the sentence), say the word for me (Deictic-pointing to the student), the past tense (Metaphoric gesture for "past tense") [Feedback-Metalinguistic cue]

Student: Achieved

Marcia: Yeah. [Now] Say this one (Deictic-pointing to the word "linked")

Student: Uhm. . .link, link, link-ed* [Error-pronunciation]

Marcia: Link-ed [Feedback-recast]

Student: Link-ed [Needs repair-same error]

Marcia: What's different about the endings? Achieved, linked. (Metaphoric 
gesture with hands outstretched encouraging the students to answer) [Feedback-elicitation]

Student: Is it T or D?

Marcia: Achieved. Linked. Why is it different? (Metaphoric gesture with hands outstretched encouraging the students to answer) [FeedbackElicitation]. . .Don't know, right?! It's a weird thing to do with the vowel, uh...not vowels, but the consonants that come before it [i.e., the -ed ending]. (Deictic gestures used throughout to point to the board as well as the throat) [Feedback-Metalinguistic explanation]

Table 4

Observed CF Episodes

\begin{tabular}{|c|c|c|c|c|}
\hline Episode & Teacher & Length & Error & CF move \\
\hline 1 & \multirow{4}{*}{ David } & $1 \mathrm{~min} 2 \mathrm{~s}$ & Morphosyntax & $\begin{array}{l}\text { Explicit Correction + } \\
\text { Metalinguistic explanation }\end{array}$ \\
\hline 2 & & $1 \mathrm{~min} 38 \mathrm{~s}$ & $\begin{array}{l}\text { Morphosyntax/Word } \\
\text { choice }\end{array}$ & $\begin{array}{l}\text { Elicitation + Explicit } \\
\text { correction + Metalinguistic } \\
\text { Explanation }\end{array}$ \\
\hline 3 & & $2 \min 16 s$ & $\begin{array}{l}\text { Morphosyntax/ } \\
\text { Referencing }\end{array}$ & $\begin{array}{l}\text { Explicit correction }+ \\
\text { Metalinguistic explanation }\end{array}$ \\
\hline 4 & & $3 \min 06 s$ & Lexical & $\begin{array}{l}\text { Elicitation + Metalinguistic } \\
\text { cue + Explanation (meaning) }\end{array}$ \\
\hline 5 & \multirow{4}{*}{ Marcia } & $1 \min 59 s$ & Word choice & Explicit correction \\
\hline 6 & & $3 \min 22 s$ & Pronunciation & $\begin{array}{l}\text { Metalinguistic cue + Recast + } \\
\text { Elicitation }(\mathrm{x} 2)+ \\
\text { Metalinguistic explanation }\end{array}$ \\
\hline 7 & & $1 \min 26 s$ & Morphosyntax & $\begin{array}{l}\text { Clarification request } \\
+ \text { Elicitation + Explicit } \\
\text { correction }\end{array}$ \\
\hline 8 & & $1 \mathrm{~min} 40 \mathrm{~s}$ & Morphosyntax & $\begin{array}{l}\text { Explicit correction }+ \\
\text { Metalinguistic explanation }\end{array}$ \\
\hline
\end{tabular}

Table 5 shows that while both teachers used gestures when supplying CF, Marcia did so more frequently $(n=170)$ compared to David $(n=106)$. The metaphoric $(n=110)$ and deictic $(n=110)$ gesture types were used the most by both teachers followed by beats $(n=35)$. The iconic $(n=17)$ and emblem types $(n=1)$ were used the least. Marcia appeared to employ the deictic $(n=70)$, metaphoric $(n=60)$, and beat types $(n=22)$ noticeably more frequently than David (40,50, and 13, respectfully); this was also true of the iconic type ( $n=$ 14 ) and emblems $(n=1)$. Three of Marcia's gestures were difficult to classify in terms of type, but this was not the case for David. 
Table 5

Gestures in CF episodes

\begin{tabular}{|c|c|c|c|c|c|c|c|c|c|c|}
\hline \multirow[t]{2}{*}{$\begin{array}{l}\text { Gesture } \\
\text { type }\end{array}$} & \multicolumn{2}{|c|}{ Episode 1} & \multicolumn{2}{|c|}{ Episode 2} & \multicolumn{2}{|c|}{ Episode 3} & \multicolumn{2}{|c|}{ Episode 4} & \multicolumn{2}{|l|}{ Total } \\
\hline & David & Marcia & David & Marcia & David & Marcia & David & Marcia & David & Marcia \\
\hline Deictic & 5 & 7 & 17 & 25 & 14 & 13 & 4 & 25 & 40 & 70 \\
\hline Iconic & 0 & 5 & 1 & 0 & 1 & 4 & 1 & 5 & 3 & 14 \\
\hline Metaphoric & 6 & 28 & 3 & 18 & 14 & 10 & 27 & 4 & 50 & 60 \\
\hline Emblems & 0 & 0 & 0 & 1 & 0 & 0 & 0 & 0 & 0 & 1 \\
\hline Beats & 0 & 13 & 0 & 6 & 5 & 1 & 8 & 2 & 13 & 22 \\
\hline \multirow[t]{2}{*}{ Ambiguous } & 0 & 2 & 0 & 0 & 0 & 0 & 0 & 1 & 0 & 3 \\
\hline & & & & & & & & & 106 & 170 \\
\hline
\end{tabular}

In terms of the communicative functions (Table 6), the teachers used gestures to complement speech the most $(n=163)$ followed by the need to provide alternate $(n=30)$ or additional $(n=46)$ information. Gestures were also used to guide speech flow $(n=18)$ and for emphasis $(n=15)$. A gesture to aid lexical retrieval was used only once, and there were three instances when the intended communicative function could not be assigned. The distribution of these was very similar between the teachers, but Marcia employed each function more frequently than David. 
Table 6

Communicative Functions Served by Gestures Used in CF Episodes

\begin{tabular}{|c|c|c|c|c|c|c|c|c|c|c|}
\hline \multirow{2}{*}{$\begin{array}{l}\text { Gesture } \\
\text { communicative } \\
\text { function }\end{array}$} & \multicolumn{2}{|c|}{ Episode 1} & \multicolumn{2}{|c|}{ Episode 2} & \multicolumn{2}{|c|}{ Episode 3} & \multicolumn{2}{|c|}{ Episode 4} & \multicolumn{2}{|l|}{ Total } \\
\hline & David & Marcia & David & Marcia & David & Marcia & David & Marcia & David & Marcia \\
\hline $\begin{array}{l}\text { Provide additional } \\
\text { information }\end{array}$ & 3 & 2 & 6 & 14 & 7 & 4 & 1 & 9 & 17 & 29 \\
\hline \multicolumn{11}{|l|}{ Enhance/ } \\
\hline $\begin{array}{l}\text { complement speech } \\
\text { content }\end{array}$ & 8 & 30 & 14 & 24 & 21 & 18 & 28 & 20 & 71 & 92 \\
\hline $\begin{array}{l}\text { Give alternate } \\
\text { information/ replace } \\
\text { speech }\end{array}$ & 0 & 9 & 1 & 6 & 1 & 5 & 4 & 4 & 6 & 24 \\
\hline $\begin{array}{l}\text { Guide/control flow of } \\
\text { speech }\end{array}$ & 0 & 8 & 0 & 1 & 3 & 1 & 3 & 2 & 6 & 12 \\
\hline $\begin{array}{l}\text { Emphasize intonation/ } \\
\text { prosody }\end{array}$ & 0 & 5 & 0 & 5 & 2 & 0 & 3 & 0 & 5 & 10 \\
\hline Aid lexical retrieval & 0 & 0 & 0 & 0 & 0 & 0 & 1 & 0 & 1 & 0 \\
\hline $\begin{array}{l}\text { Aid lexical sentence } \\
\text { reconstruction }\end{array}$ & 0 & 0 & 0 & 0 & 0 & 0 & 0 & 0 & 0 & 0 \\
\hline \multirow[t]{2}{*}{ Ambiguous } & 0 & 1 & 0 & 1 & 0 & 0 & 0 & 1 & 0 & 3 \\
\hline & & & & & & & & & 106 & 170 \\
\hline
\end{tabular}


In the stimulated recall sessions, when the teachers were asked to explain why they used gestures in their EAP lessons, they spoke of gestures' ability to complement and enhance the meaning conveyed in speech, which they felt was especially important for L2 learners who struggle to attend to both meaning and form: "to reinforce verbal. . if you can add to facial, nonverbal they [the students] understand it much clearer" (David). By using gestures, the teachers could "draw their [students'] attention to something [in the input]," and for Marcia in particular, she was "literally trying to do it with" her body. To raise learner awareness about linguistic structures and their importance for accuracy, the two would choose gestures strategically. Marcia, for example, would regularly use the metaphoric gesture of pointing the index finger with the hand raised horizontally towards the temple to alert learners to focus on what was happening in the moment and the need to reflect: "I'm trying to get them to think: C'mon. You have to process it." Similarly, David, spoke of using a beats gesture, where with a closed fist he moved his arm up and down while aligning his timing with the intonation in his speech, to reinforce verbal input: "if they [the students] don't pick up on it [the emphasis from the gesture] consciously, I think it [the gesture] reinforces [the meaning]".

Both teachers reported learner proficiency level as the catalyst in their decision of the type and number of gestures to use. That is, the lower the level, the more gestures they felt they needed to utilize. David, for example, felt that for "lower level students, it's even more important [to see] the nonverbal." He based this view on his experiences teaching in the EFL context: "I tend to be more animated, and that probably came from [my] EFL classes to lower-level students where you need to kind of engage, not just by speaking, but visually." The teaching context also matters to gesture use. Marcia, for example, recounted an experience of teaching online in a 3D virtual environment and her inability to employ gestures as she regularly would in the face-to-face setting of a classroom. Working with a group of lowintermediate learners, she had to rely on verbal commands and explanations, for which, she felt, her students were not ready: "I had no way to tell them what I mean other than words. For a lot of these guys their language level is intermediate, low-intermediate, they need it [visually enhanced input]." Finally, realizing that low proficiency and the cultural aspect inherent to gesture use can give rise to communicative misunderstandings and possibly lead to class disharmony, the teachers in this study were careful in choosing gestures for the classroom: "when you're intercultural with people from different cultures, you have to be very aware... dealing with culture needs to be considered when using gestures" (David). They also felt that it is their duty to inform learners of the gestures they would likely encounter at university and how to interpret them correctly: "University gesture is so mixed; you need to be aware of what you should and shouldn't do" (David). 


\section{Discussion}

\section{Gestures}

This study explored the gestures two university-level EAP teachers used in their teaching practice in general and alongside CF episodes to then juxtapose these with the teachers' thoughts on gesture use before and after the observations. The findings show that, similar to what they said in the interviews, the two teachers frequently used gestures in their practice and did so with purpose. Specifically, they employed most of the gesture types described by McNeil (1992) - with deictic, metaphoric, and beats occurring most frequently - to enhance/complement, provide additional or alternate information, guide speech flow, and emphasize particular portions of oral discourse. This is in line with the findings of other observational studies on gesture use in language classrooms that reported teachers employing nonverbal cues, including gestures, to complement verbal input, monitor turn-taking in conversations, react to speech, explain vocabulary items, and teach L2 pronunciation (e.g., Allen, 1995, 2000; Hudson, 2011; Lazaraton, 2004; Smotrova, 2017; Smotrova \& Lantolf, 2013). In this study, the teachers' awareness of the extent of their gesture use is also noteworthy for it is often not the case among language teachers (e.g., Lazaraton, 2004; Nardotto Peltier \& McCafferty, 2010).

The frequency of employing gestures differed with the two teachers as Marcia utilized a total of 1,000 gestures in the hour observed whereas David used 561 gestures. This finding aligns with the teachers' stated importance of gestures in their teaching, with Marcia living up to her self-described teaching "with her whole body" and David using gestures to appear animated and to engage learners. Frequent use of gestures, relaxed demeanor, and positive facial expressions can contribute to a positive classroom environment, which may impact learners' emotional readiness to participate in learning and remain motivated to learn (Sime, 2006). Using a stimulated recall, Sime (2006) had EFL learners comment on their in-class teachers' use of gestures and nonverbal behaviours. They appreciated teachers' gestures, which they saw as instrumental in enhancing the learning process, reflective of the teachers' emotions and attitudes, and facilitative of classroom management. In fact, they expected teachers to organize class interactions and direct turn-takingclassroom management moves that are often signalled or accompanied by gestures. The teachers in this study also spoke of gestures as tools to manage the classroom and students' emotions. They enacted their perceptions by employing deictic gestures and emblems. That is, while the former were used to set up tasks, group learners, or call on particular students to respond, the latter could, for example, signal approval (e.g., a thumbs up gesture) or request an additional attempt (e.g., index finger wagging). To support learners' positive disposition towards a task/class environment and encourage 
language use, the teachers in this study incorporated beats to support the flow of output or to help with word recall; iconic gestures also facilitated lexical retrieval. When comprehension was impeded, teachers employed metaphoric gestures to determine and/or illustrate the intended meaning. Perhaps, the frustration that Marcia recounted feeling when teaching in a $3 \mathrm{D}$ online setting stemmed from her inability to use gestures to manage and positively affect the learning process she was in charge of.

The teachers reported the need to incorporate more gestures when teaching lower-proficiency learners for they saw gestures as enhancers of comprehension. Although this study did not observe the teachers working with groups of different proficiencies, this view is echoed in Lazaraton (2004), where the teacher spoke of using gestures to aid beginner and intermediate ESL learners' comprehension and to encourage them to participate in interactions. Experimental gesture research has also shown that visual cues can improve comprehension, especially when L2 proficiency is reduced (e.g., Dahl \& Ludwigsen, 2014; McCafferty, 2002; Sueyoshi \& Hardison, 2005).

The teachers spoke about the role culture plays in the use and interpretation of gestures and reported being careful in employing gestures whose meaning could inadvertently be misconstrued. This is in line with the advice that teachers should be vigilant in their use of gestures and that they should alert learners to the cultural norms of the context they share (e.g., Allen, 2000; Hudson, 2011; Lazaraton \& Ishihara, 2005). In-class discussions that address these differences can not only clarify the intended meaning of gestures and improve comprehension, but also bring about or strengthen the positive classroom environment that the two teachers sought to create and maintain through gestures. After all, learners tend to internalize gestures they are exposed to in L2 contexts, even when these diverge from the L1-specific ones (e.g., McCafferty, 1998, 2002, 2008). Furthermore, since recognizing cultural differences in the use of gestures can promote learners' self-regulation and communication in the L2 (e.g., Lee, 2008; McCafferty, 2006; Negueruela \& Lantolf, 2008), teachers are encouraged to train learners in the use and significance of L2-specific gestures (Gregersen \& MacIntyre, 2017).

\section{Gestures and CF}

In terms of $\mathrm{CF}$, each teacher in this study spent a fraction of the lesson $(12.5 \%$ for Marcia; $12.7 \%$ for David) on issues of form, which is notably less than the rates reported in other CF studies (e.g., Ellis et al., 2001; Fu \& Nassaji, 2016; Nassaji \& Kartchava, 2020). In Kartchava (2019), for example, 35 minutes of intensive CF provision yielded more feedback (77\%). The instructional context could be one reason for the result as these studies considered teachers in settings that differed in curricula, approaches, and discourse types. Also, the teachers in this study spoke of being selective when they provide $\mathrm{CF}$, choosing to focus on the EAP skills that demand accuracy (grammar and 
writing) and contextualizing CF within tasks that promote focus on form. Research has shown that teachers address grammatical errors more than lexical and phonological ones despite learners' reacting more to the latter targets (e.g., Brown, 2016; Lyster, 1998; Mackey et al., 2000). Still, there is evidence that salient grammatical targets are amenable to CF (Nassaji, 2015, 2016). The teachers favoured explicit CF types, such as explicit correction and metalinguistic explanations. Marcia, in fact, was explicit in her preference for prompts, perceiving them as attention-getters and more effective in leading to L2 development. Yet, she was cognisant that these are effective when the corrective intent is recognized and learners know the target rule/structure. This preference can also be explained by the learners' lower proficiency and prompts being more noticeable (e.g., Kartchava \& Ammar, 2013) and beneficial (e.g., Ammar \& Spada, 2006) than recasts. Notably, the teachers implemented several strategies in providing $\mathrm{CF}$, often starting with more implicit prompts and moving towards more explicit ones, a move supported by research (e.g., Nassaj, 2007, 2011). Finally, the teachers spoke about the importance of training learners to recognise the codes they used when providing written CF since they saw them as another way to help learners recognize the corrective nature of the feedback, pushing them towards increased autonomy and eventual L2 success (see Kartchava, in press).

Because learners need to notice $\mathrm{CF}$ to benefit from it, the two teachers used gestures in CF episodes to support verbal feedback. They did so with deictic, metaphoric, and beat gestures to enhance/complement speech and to provide additional information. The choice and amount of gesture use was also dictated by the low proficiency of the learners as both teachers reported the need to supply more gestures than they would with more advanced learners. The notable dominance of deictics for both teachers testifies to their expressed need to draw learners' attention to specific issues or to engage them in correction. Metaphoric gestures were especially prominent in Marcia's discourse, who saw them as effective signals for learners to focus on what was happening in the lesson. Similarly, David employed beats to reinforce verbal input. Hence, they saw gestures as another form of input to draw learners' attention to form, aid comprehension, and affect learning (Gullberg, 2006). It is then not surprising that the teachers used gestures to support both explicit and implicit CF types. Finally, the differences in the amount and type of gesture used speak to the participants' teaching styles, focus of instruction, and the nature of CF (Wang \& Loewen, 2016).

\section{Conclusion}

The findings of this small-scale study suggest that EAP teachers use various gestures in their teaching and when providing corrective feedback. They are also aware of the reasons for their actions and are strategic in their implementation. This congruence is notable in light of research 
demonstrating that teachers are not always aware of their gesture use, which can confuse learners. Understanding the fundamentality of gestures in teaching (Lazaraton, 2004), the instructors utilized them to attract learners' attention in targeting concepts/items, including errors, ensure understanding, provide additional or alternate information, set up tasks, and to manage the classroom. In CF episodes, gestures emphasized the corrective intent of the moves employed, likely amplifying their saliency. This investigation adds to our understanding of the role of gestures in the teaching of academic English and provides evidence on how teachers incorporate gestures in general as well as when providing feedback in this setting. It suggests that nonverbal feedback has a role to play in EAP classrooms and that its utility may aid teachers in providing corrective information (even if infrequently). To benefit from these advantages, teachers should become aware of their nonverbal behaviour, inform learners of its utility (especially those at the lower proficiency), and encourage its use.

The limited amount of class time and the number of teachers observed, however, are limitations of this study, as is the fact that learner uptake was not examined. Future investigations could build on this study by investigating learners' understanding of and reactions to teachers' gestural and other nonverbal feedback (including gaze) as well as consider the practices of both teachers and learners in other settings, with different linguistic targets, proficiencies, and languages. The effectiveness of the various nonverbal feedback types in facilitating L2 development could also be examined.

\section{Notes}

1. Although beyond the scope of this study, it is important to note that gestures can have both speaker-internal and speaker-external functions that facilitate communication by helping speakers to organize their thoughts, and listeners to streamline comprehension (see McCafferty, 2004).

\section{Acknowledgement}

We extend our sincere thanks to the participants who made this research possible and to the reviewers for their insightful comments. Any errors that remain are ours alone.

\section{The Authors}

Eva Kartchava is an associated professor of applied linguistics and TESL at Carleton University. She is interested in and has published research on the relationship between corrective feedback and second language learning/teaching, noticeability of feedback, and the role of individual differences in the language learning process.

Abdizalon Mohamed is an MA candidate in the Applied Linguistics and Discourse Studies program at Carleton University. This study is based on his MA thesis research. 


\section{References}

Allen, L. Q. (1995). The effects of emblematic gestures on the development and access of mental representations of French expressions. Modern Language Journal, 79(4), 521-529.

Allen, L. Q. (2000). Nonverbal accommodations in foreign language teacher talk. Applied Language Learning, 11, 155-176.

Ammar, A., \& Spada, N. (2006). One size fits all? Recasts, prompts and L2 learning. Studies in Second Language Acquisition, 28, 543-574.

Ammar, A. (2008). Prompts and recasts: Differential effects on second language morphosyntax. Language Teaching Research, 12(2), 183-210.

Brown, D. (2014). The type of linguistic foci of oral corrective feedback in the L2 classroom: A meta-analysis. Language Teaching Research, 20(4), 436-458.

Brown, D. (2016). The type and linguistic foci of oral corrective feedback in the L2 classroom: A meta-analysis. Language Teaching Research, 20, 436-458.

Brugman, H., \& A. Russell (2004). Annotating multi-media/multi-modal resources with ELAN. In Proceedings of LREC 2004, Fourth International Conference on Language Resources and Evaluation.

Carroll, S. (2001). Input and evidence: The raw material of second language acquisition: Volume 25. Philadelphia, PA: John Benjamins.

Dahl, T. I., \& Ludvigsen, S. (2014). How I see what you're saying: The role of gestures in native and foreign language listening comprehension. The Modern Language Journal, 98(3), 813-833.

Davies, M. (2006). Paralinguistic focus on form. TESOL Quarterly, 40(4), 841-855.

Dörnyei, Z. (2007). Research methods in applied linguistics: Quantitative, qualitative, and mixed methodologies. Oxford, UK: Oxford University Press.

ELAN (Version 5.8) [Computer software]. (2019). Nijmegen: Max Plank Institute for Psycholinguistics. The Language Archive. Retrieved from https://archive.mpi.nl/yla/elan

Ellis, R., Loewen, S., \& Erlam, R. (2006). Implicit and explicit corrective feedback and the acquisition of L2 grammar. Studies in Second Language Acquisition, 28(3), 339-368.

$\mathrm{Fu}, \mathrm{T}$., \& Nassaji, H. (2016). Corrective feedback, learner uptake, and feedback perception in a Chinese as a foreign language classroom. Studies in Second Language Learning and Teaching, 6, 161-183.

Gass, S. M., \& Mackey, A. (2000). Stimulated recall methodology in second language research. Mahwah, NJ: Lawrence Erlbaum Associates.

Gibson, W., \& Brown, A. (2009). Working with qualitative data. Los Angeles, CA: SAGE.

Gluhareva, D., \& Prieto, P. (2017). Training with rhythmic beat gestures benefits L2 pronunciation in discourse-demanding situations. Language Teaching Research, 21(5), 609-631.

Goo, J., \& Mackey, A. (2013). The case against the case against recasts. Studies in Second Language Acquisition, 35, 127-165.

Gregersen, T., \& MacIntyre, P. D. (2017). Optimizing language learners' nonverbal behaviour: From tenet to technique. Bristol, UK: Multilingual Matters.

Gullberg, M. (2006). Some reasons for studying gesture and second language acquisition (Hommage à Adam Kendon). International Review of Applied Linguistics in Language Teaching, $44,103-124$.

Hudson, N. (2011). Teacher gesture in a post-secondary English as a second language classroom: A sociocultural approach [Unpublished doctoral dissertation]. University of Nevada, Las Vegas, Nevada.

Hyland, K. (2006). English for academic purposes: An advanced resource book. New York: Routledge.

Inceoglu, S. (2015). Teacher gesture and lexical focus on form in a foreign language classroom. Canadian Modern Language Review, 71(2), 130-154.

Kamiya, N. (2012). Proactive and reactive focus on form and gestures in EFL classrooms in Japan. System, 40(3), 386-397.

Kartchava, E. (2019). Chapter 5: Nonverbal behaviour and corrective feedback. In Noticing oral corrective feedback in the second language classroom: Background and evidence. Lexington Books.

Kartchava, E. (in press). The role of training in feedback provision and effectiveness. In H. Nassaji 
\& E. Kartchava (Eds.), The Cambridge Handbook of Corrective Feedback in Second Language Learning and Teaching. Cambridge University Press.

Kartchava, E., \& Ammar, A. (2013). Noticing and learning: Relationship patterns. Study in English Language Teaching, 1(1), 8-25.

Kartchava, E., \& Ammar, A. (2014). The noticeability and effectiveness of corrective feedback in relation to target type. Language Teaching Research, 18(4), 428-452.

Kendon, A. (2004). Gesture: Visible action as utterance. Cambridge, UK: Cambridge University Press.

Kong, A., Law, S., Kwan, C., Lai, C., \& Lam, V. (2015). A coding system with independent annotations of gesture forms and functions during verbal communication: Development of a Database of Speech and GEsture (DoSaGE). Journal of Nonverbal Behavior, 39(1), 93-111.

Lazaraton, A. (2004). Gesture and speech in the vocabulary explanations of one ESL teacher: A microanalytic inquiry. Language Learning, 54(1), 79-117.

Lazaraton, A., \& Ishihara, N. (2005). Understanding second language teacher practice using microanalysis and self-reflection: A collaborative case study. The Modern Language Journal, $89,529-542$.

Lee, J. (2008). Gesture and private speech in second language acquisition. Studies in Second Language Acquisition, 30, 169-190.

Li, S. (2010). The effectiveness of corrective feedback in SLA: A meta-analysis. Language Learning, 60(2), 309-365.

Loewen, S. (2012). The role of feedback. In S. M. Gass \& A. Mackey (Eds.), The Routledge handbook of second language acquisition (pp. 24-40). Routledge.

Loewen, S., \& Philp, J. (2006). Recasts in the adult L2 classroom: characteristics, explicitness and effectiveness. Modern Language Journal, 90, 536-556.

Lyster, R. (1998). Negotiation of form, recasts, and explicit correction in relation to error types and learner repair in immersion classrooms. Language Learning, 48, 183-218.

Lyster, R., \& Mori, H. (2006). Interactional feedback and instructional counterbalance. Studies in Second Language Acquisition, 28, 269-300.

Lyster, R., \& Ranta, L. (1997). Corrective feedback and learner uptake: Negotiation of form in communicative classrooms. Studies in Second Language Acquisition, 19, 37-66.

Lyster, R., \& Ranta, L. (2013). Counterpoint piece: The case for variety in corrective feedback research. Studies in Second Language Acquisition, 35, 167-184.

Lyster, R., Saito, K., \& Sato, M. (2013). Oral corrective feedback in second language classrooms. Language Teaching, 46(1), 1-40.

Macedonia, M., Müller, K., \& Friederici, A. D. (2011). The impact of iconic gestures on foreign language word learning and its neural substrate. Human Brain Mapping, 32(6), 982-998.

Mackey, A. (2006). Feedback, noticing and instructed second language learning. Applied Linguistics, 27(3), 405-430.

Mackey, A., Gass, S. M., \& McDonough, K. (2000). How do learners perceive implicit negative feedback? Studies in Second Language Acquisition, 22, 471-497.

Mackey, A., \& Goo, J. (2007). Interaction research in SLA: A meta-analysis and research synthesis. In A. Mackey (Ed.), Conversational interaction and second language acquisition. A series of empirical studies (pp. 377-419). Oxford University Press.

Mackey, A., \& Philp, J. (1998). Conversational interaction and second language development: Recasts, responses, and red herrings? Modern Language Journal, 82, 338-356.

Manusov, V. (2016). A history of research on nonverbal communication: Our divergent pasts and their contemporary legacies. In D. Matsumoto, H. C. Hwang, \& M. G. Frank (Eds.), APA handbooks in psychology®. APA handbook of nonverbal communication (p. 3-15). American Psychological Association. https://doi.org/10.1037/14669-001

McCafferty, S. G. (1998). Nonverbal expression and L2 private speech. Applied Linguistics, 19, 73-96.

McCafferty, S. G. (2002). Gesture and creating zones of proximal development for second 
language learning. Modern Language Journal, 86, 192-203.

McCafferty, S. G. (2004). Space for cognition: Gesture and second language learning. International Journal of Applied Linguistics, 14(1), 148-165.

McCafferty, S. G. (2006). Gesture and the materialization of second language prosody. International Review of Applied Linguistics, 44, 197-209.

McCafferty, S. G. (2008). Material foundations for second language acquisition: Gesture, metaphor, and internalization. In S. G. McCafferty \& G. Stam (Eds.), Gesture: Second language acquisition and classroom research (pp. 47-65). New York: Routledge.

McNeill, D. (1992). Hand and mind: What gestures reveal about thought. Chicago, IL: University of Chicago Press.

McNeil, D. (2006). Gesture and thought. Chicago: The University of Chicago Press.

Morett, L. M., \& Chang, L. Y. (2015). Emphasising sound and meaning: Pitch gestures enhance Mandarin lexical tone acquisition. Language, Cognition and Neuroscience, 30(3), 347-353.

Nabei, T., \& Swain, M. (2002). Learner awareness of recasts in classroom interaction: A case study of an adult EFL student's second language learning. Language Awareness, 11, 43-63.

Nakatsukasa, K. (2016). Efficacy of recasts and gestures on the acquisition of locative prepositions. Studies in Second Language Acquisition, 38(4), 771-799.

Nakatsukasa, K. (2019). Using gesture-enhanced recasts for teaching English past tense: A case when gestures do not work. Language Teaching Research. https://doi. org/10.1177/1362168819870283

Nakatsukasa, K. (in press). Gestures, corrective feedback, and second language development. In H. Nassaji \& E. Kartchava (Eds.), The Cambridge handbook of corrective feedback in second language learning and teaching. Cambridge University Press.

Nakatsukasa, K., \& Loewen, S. (2017). Non-verbal feedback. In H. Nassaji \& E. Kartchava (Eds.), Corrective feedback in second language teaching and learning: Research, theory, applications, implications (pp. 158-173). Oxon, UK: Routledge.

Nardotto Peltier, I., \& McCafferty, S. G. (2010). Gesture and identity in the teaching and learning of Italian. Mind, Culture, and Activity, 17, 1-19.

Nassaji, H. (2007). Elicitation and reformulation and their relationship with learner repair in dyadic interaction. Language Learning, 57, 511-548.

Nassaji, H. (2011). Correcting students' written grammatical errors: The effects of negotiated versus nonnegotiated feedback. Studies in Second Language Learning and Teaching, 1, 315-334.

Nassaji, H. (2015). Interactional feedback dimension in instructed second language learning. London: Bloomsbury Publishing.

Nassaji, H. (2016). Anniversary article: Interactional feedback in second language teaching and learning: A synthesis and analysis of current research. Language Teaching Research, 20, 535562.

Nassaji, H., \& Kartchava, E. (2020). Corrective feedback and the good language teachers. In C. Griffiths \& Z. Tajeddin (Eds.), Lessons from good language teachers (pp. 151-163). Cambridge, UK: Cambridge University Press.

Negueruela, E., \& Lantolf, J. P. (2008). The dialectics of gesture in the construction of meaning in second language oral narratives. In S. G. McCafferty \& G. Stam (Eds.), Gesture: Second language acquisition and classroom research (pp. 88-106). New York: Routledge.

Repetto, C., Pedroli, E., \& Macedonia, M. (2017). Enrichment effects of gestures and pictures on abstract words in a second language. Frontiers in Psychology, 8, 2136. https://doi.org/10.3389/ fpsyg.2017.02136

Russell, J., \& Spada, N. (2006). The effectiveness of corrective feedback for second language acquisition: A meta-analysis of the research. In J. Norris \& L. Ortega (Eds.), Synthesizing research on language learning and teaching (pp. 133-164). John Benjamins.

Saldaña, J. (2016). The coding manual for qualitative researchers (3rd ed.). Los Angeles, CA: SAGE.

Sheen, Y. (2004). Corrective feedback and learner uptake in communicative classrooms across instructional settings. Language Teaching Research, 8, 263-300. 
Sheen, Y. (2006). Exploring the relationship between characteristics of recasts and learner uptake. Language Teaching Research, 10, 361-392.

Sheen, Y., \& Ellis, R. (2011). Corrective feedback in language teaching. In E. Hinkel (Ed.), Handbook of research in second language teaching and learning (pp. 593-610). New York, NY: Routledge.

Sime, D. (2006). What do learners make of teachers' gestures in the language classroom? International Review of Applied Linguistics, 44, 211-230.

Sime, D. (2008). "Because of her gesture, it's very easy to understand": Learner's perceptions of teacher's gestures in the foreign language class. In S. G. McCafferty \& G. Stam (Eds.), Gesture in second language acquisition and classroom research (pp. 259-279). London, England: Routledge.

Smotrova, T. (2017). Making pronunciation visible: Gesture in teaching pronunciation. TESOL Quarterly, 51(1), 59-88.

Smotrova, T., \& Lantolf, J. P. (2013). The function of gesture in lexically focused L2 instructional conversations. The Modern Language Journal, 97(2), 397-416.

Sueyoshi, A., \& Hardison, D. M. (2005). The role of gestures and facial cues in second language listening comprehension. Language Learning, 55(4), 661-699.

Tellier, M. (2008). The effect of gestures on second language memorisation by young children. Gesture, 8, 219-235.

Wang, W., \& Loewen, S. (2016). Nonverbal behaviour and corrective feedback in nine ESL university-level classrooms. Language Teaching Research, 20, 459-478.

Wittenburg, P., Brugman, H., Russel, A., Klassmann, A., \& Sloetjes, H. (2006). ELAN: A professional framework for multimodality research. In Proceedings of LREC 2006, Fifth International Conference on Language Resources and Evaluation. 